Egyptian

Orthodontic Journal

\title{
EGYPTIAN PREDICTION CHART FOR MIXED DENTITION ANALYSIS USING MOYER'S METHOD
}

\author{
Mohamed Ehab EL-Kattan* \\ Nevine Waly** \\ Fatma El-Shehaby***
}

ABSTRACT

The purpose of this study was to evaluate Moyer's prediction chart, 6y application of this chart on Egyptian sample, and to develop an Egyptians prediction chart 6ased on the Egyptian 6ackground.

318 upper and lower study casts of patients ranging in age between 13-18 years were collected from the records of Orthodontic department Faculty of Oral and Dental Medicine, Cairo University.

The misiodistal widths of the upper and lower incisors, and the upper and lower canine and premolars were measured by boley gauge graduated to the nearest $0.1 \mathrm{~mm}$. Also the perimeters of the upper and lower arches were measured between the mesial surfaces of the first permanent molars along the arch, by the segmented technique. From the results of this study the following conclusion can be drawn: 1. Moyer's prediction chart was found to be not applicable to the Egyptian sample under the 75\% probability level. 2. The Moyer's chart overestimated the misiodistal widths of the upper and lower canine and premolars. 3. the probability confidence levels of Moyer's chart (5-35\%) were found to be the nearest prediction figures to the Egyptian sample.

\footnotetext{
* B.Ds. of Oral and Dental Medicine, Cairo University

** Professor of Pediatric Dentistry. Faculty of Oral and Dental Medicine, Cairo University

*** Ass. Professor of Pediatric Dentistry. Faculty of Oral and Dental Medicine, Cairo University
} 
Egyptian

Orthodontic Journal

\section{INTRODUCTION}

Several methods of mixed dentition analysis have been suggested to evaluate the amount of space available in dental arch. However all methods fall into two strategic categories. These in which the size of the unerupted cuspids and premolars are estimated from measurements of the radiographic image, and those in which the sizes of the cuspids and premolars are derived from knowledge of the sizes of permanent teeth already erupted in the mouth using prediction equation or chart. Errors in film adjustment, magnification, distortion and high cost of equipment may be the disadvantage of the radiographic method.

In 1902 Black measured a large number of human teeth and setup tables of mean figures for each tooth in the dental arch. Ballard (1944) compared the mesiodistal width of teeth of one side with those of corresponding teeth on the other side. The author concluded that lack of harmony between tooth mass and the amount of supporting base was manifested in rotations and blocked anterior teeth.

Ballard and Wylie (1947) studied the relationship of the mandibular incisors and the sum of the mandibular canine, first and second premolars. They found a moderate coefficient of correlation. They made a formula to predict the sum of the mandibular canine, first and second premolars. The formula was $\mathrm{X}=9.41+0.525 \mathrm{Y}$, where $\mathrm{x}$ equals the sum of the mandibular canine, first and second premolars of one side, $\mathrm{Y}$ equals the sum of the four mandibular incisors. The researchers found the estimated error from the use of their predictive formula about $2.6 \%$.

Hixon and Old father in (1958) developed a method of predicting the mesiodistal width of mandibular canine and premolars, based on measurement of persons who participated in the Iawa facial Growth Study Subjects. The researchers measured the mesiodistal widths of the lower incisors on the cast for one side and the mesiodistal widths of the first and second premolars from periapical radiographs. They did not measure the width of lower canine from the radiograph, as they found it was difficult to be measured on the radiograph. They predicted the mesiodistal widths of lower canines and premolars for one side from a predicting graph using the sum of lower incisors and premolars.

Tanaka and Johnston in (1974), studied 506 recent orthodontic patients to develop a linear regression equation for the prediction of the mesiodistal widths of unerupted canines and premolars. In the maxillary segment (canine and 
premolars in one quadrant) equal one half of the mesiodistal width of the four lower incisors plus $11.0 \mathrm{~mm}$, while in the mandibular segment equal one half of the mesiodistal widths of the four lower incisors plus $10.5 \mathrm{~mm}$.

As regards prediction chart or equation method using the sizes of the permanent teeth which have already erupted in the mouth (lower incisors) to predict the sizes of the unerupted teeth (canines and premolars) there is no need for equipments or radiographic images. Prediction chart or equation is the only requirement. Moyer's prediction chart is one of the most popular methods in the mixed dentition analysis. In 1958 Moyer published prediction chart based on a correlation between the combined widths of the mandibular incisors and the combined widths of the mandibular and maxillary canines and premolars. $\mathrm{He}$ suggested that maxillary incisors are not used in any of the predicting procedures, since they show too much variability in size, and their correlation with other groups of teeth are low to be of a practical value. Therefore the lower incisors are measured to predict the size of the upper as well as the lower canines and premolars. Moyer recommended using the $75 \%$ level of probability, as clinically this gives more protection from crowding. Unfortunately, the racial difference may be a reason that it may not be applicable on Egyptian children.

In 1987, El-Kattan and Eid evaluated the reliability of Moyer's prediction chart for mixed dentition analysis. They studied longitudinally 29 Egyptian girls between the mixed and early permanent dentition periods. They found that there was a significant decrease in the sum of the upper and lower canine and premolars, when the chart was used for the Egyptian sample. They concluded that prediction chart based on Egyptian data would be necessary, An attempt was made by El-Kattan and Eid in $\mathbf{1 9 8 8}$ to develop Egyptian prediction chart. They used dental casts for 42 boys and 38 girls aged 131/2 to $141 \frac{1}{2}$ years to correlate mesiodistal widths of the lower incisors to the upper and lower canines and premolars in one side. Regression analysis was used to construct the Egyptian prediction chart for mixed dentition analysis.

Al Khadra in 1993 criticized the commonly used prediction methods of Moyers and Tanaka and Johnston based on data from a sample of children of Northern European descent. The authors applied the Moyer probability tables to a limited sample of a Saudi Arab population. They found the 35\% level was a more accurate determinant than the commonly used $75 \%$ confidence level. The prediction equations of Tanaka and Johnston overestimated the size of buccal segments in their population. The data illustrated the limitations of these methods when applied to population of other than Europe descent. They developed two linear regression equations for tooth size prediction in Saudi Arab children. 
Jaroonthan and Godfrey in 2000 collected dental casts of 215 boys and 215 girls (mean age 15.7 years) free of any signs of dental pathology or anomalies. They found that males had significantly larger teeth than females. The regression equations produced predictions of mesio-distal width summations for maxillary and mandibular canine and premolar arch segments that were slightly different from other reported Asian studies. Moyer's prediction tables at the $50^{\text {th }}$ percentile were found to underestimate tooth size summation compared with their investigation. They made the equations for males and females separately.

Flores et al., in 2003, compared between Tanaka-Johnston and Moyer's' methods for mixed dentition analysis. They used 248 dental casts. The results showed that Tanaka Johnston regression equation was not precise, except for the upper arch in the male sample. For females, the Moyer's' $95^{\text {th }}$ percentile in the upper arch and the $65^{\text {th }}$ percentile in the lower arch predicted the sum precisely for males, the Moyer's 65 percentile for the lower arch predicted the sum precisely but none of the Moyer's' percentiles provided precise prediction in the upper arch for females. They concluded that using tooth width prediction methods from a different racial origin could create an under or overestimation of the actual combined canine and premolars tooth width.

In 2003, Hushim and Al-Sholan, analyzed 65 Saudi subjects (37 males and 28 females) aged 18-25 years, to produce an estimated equation for the prediction of unerupted cuspids and bicuspids for the Saudi population. It was found that the Tanaka Johnson equations overestimated the tooth widths in Saudis. The predicted tooth width of Saudis (males and females) was closer to the 50\% level of confidence in Moyers chart. Therefore, they developed equations for the Saudi males and females.

Bernabe and Flores in 2004, emphasized that it is important not only to evaluate the statistical need for specific single linear regression equation in different population, but also to state the clinical significance of their differences against commonly used equations.

Martinelli et al., in 2005, studied 30 white Caucasian patients Orthodontically treated at the Faculty of Dentistry, Universidad Federa do Rio de Janeiro. The records of every patient included a 45 degrees oblique tele-radiograph (left side) in the mixed dentition period and a dental cast of the permanent dentition. Pearson's test was applied between each lower canine, first and second premolars measured on the radiograph, and the sum of their actual widths measured on the dental cast. 
So the aim of this Study is, evaluation of Moyer's mixed dentition analysis method when applied on an Egyptian sample and to develop an Egyptian prediction chart based on Egyptian data.

\section{Materials \& Methods}

The sample consisted of 318 upper and lower dental study casts (120 males and 198 females) randomly selected from the records of the Orthodontic Department, Faculty of Oral and Dental Medicine, Cairo University. The age of the subjects included in the sample ranged between 13-18 years.

\section{Criteria of selection}

1. All the casts were made from stone plaster*.

2. All the upper and lower permanent teeth were presented, except the third molar.

3. No one of them was subjected to orthodontic treatment.

4. The study casts were free of visible fractures, badly decayed and malformed tooth or teeth.

5. All the casts belonged to Egyptian patients.

\section{Materials used for measurements:}

1. A boley gauge ${ }^{* *}$ graduated to the nearest $0.1 \mathrm{~mm}$.

2. Moyer's prediction charts (Moyer 1958-1973 appendix page).

3. Chart for recording data.

\section{Measurements}

1. The mesiodistal crown diameters of the maxillary and mandibular central, lateral incisors, canines, first and second premolars were measured on the casts as the greatest distance between the proximal surfaces of the teeth with the boley gauge held parallel to the occlusal plane.

2. The perimeter or circumference was measured by dividing the arch into 4 straight line segments.

* Moldano-Bayer-Germany

** 092-750 Dentaurum 
- From the mesial surface of the right first permanent molar to the tip of right permanent canine.

- From the tip of right permanent canine to the midline between the to central incisors.

- From the midline between the two central incisors to the tip of the left permanent canine.

- From the tip of left permanent canine to the mesial surface of the left permanent first molar.

The boley gauge was held parallel to the occlusal plane and the 4 segments were measured individually. The sum of the segments is equal to the arch perimeter.

\section{Method error}

The researcher repeated his measurements of 30 casts on two occasions. Dahlberg's formula, method error $=\frac{(\mathrm{cd}-\mathrm{d})^{2}}{2 \mathrm{n}}$ was applied to the difference between the initial and repeated measurements. Where (d) is the difference, (d') the mean difference between the first and second records, and (n) the number of double determinations. The deviation of measurements fell within the accepted range of accuracy (less than 0-5 $\mathrm{mm}$ ).

\section{Statistical analysis:}

Data management and analysis were performed using statistical analysis systems (SAS, 1988), the graphs done using Microsoft Word and Harvard Graphics. An IBM Pentium 4 was used. Data were summarized using means and standard deviations as well as the $95 \%$ confidence intervals. The distribution of the cases was compared to Moyer's prediction chart using the chi-square goodness of fit test. Prediction equations were developed to predict the size of maxillary and mandibular cupids and bicuspids from the size of the sum of the upper and lower incisors. These equations used the linear regression equation $y=$ intercept + slop sum of upper or lower incisors. The measurements developed from these equations were compared to the Moyer's probability chart at the $5^{\text {th }}, 25^{\text {th }}, 35^{\text {th }}$ and $75^{\text {th }}$ percentile confidence levels (Dawson and Trapp, 2001). All p-values which were two-sided p-values $<0.05$ were considered significant. 
Egyptian

Orthodontic Journal

\section{RESULTS}

Table1: the mean, standard deviation, at 95\% confidence intervals, and range of the mesiodistal width for all groups.

\begin{tabular}{|c|c|c|c|c|c|c|c|c|}
\hline \multirow[b]{2}{*}{ Jaw } & \multirow[b]{2}{*}{ Tooth } & \multicolumn{7}{|c|}{$95 \% \mathrm{CI}$} \\
\hline & & $\mathrm{N}$ & Mean & Std Dev & Lower & Upper & Minimum & Maximum \\
\hline \multicolumn{9}{|c|}{ Upper Left } \\
\hline & 5 & 318 & 6.69 & 0.55 & 6.63 & 6.75 & 5.40 & 9.00 \\
\hline & 4 & 318 & 6.98 & 0.52 & 6.92 & 7.04 & 5.00 & 8.70 \\
\hline & 3 & 318 & 7.40 & 0.72 & 7.32 & 7.48 & 3.00 & 9.50 \\
\hline & 2 & 318 & 6.77 & 0.67 & 6.69 & 6.84 & 4.50 & 8.40 \\
\hline & 1 & 318 & 8.63 & 0.67 & 8.56 & 8.70 & 5.40 & 10.50 \\
\hline \multicolumn{9}{|c|}{ Upper Right } \\
\hline & 1 & 318 & 8.60 & 0.68 & 8.53 & 8.68 & 5.40 & 11.00 \\
\hline & 2 & 318 & 6.75 & 0.62 & 6.68 & 6.82 & 5.00 & 8.50 \\
\hline & 3 & 318 & 7.40 & 0.71 & 7.32 & 7.48 & 3.70 & 9.50 \\
\hline & 4 & 318 & 6.98 & 0.50 & 6.93 & 7.04 & 5.70 & 8.60 \\
\hline & 5 & 318 & 6.65 & 0.57 & 6.59 & 6.71 & 4.50 & 9.00 \\
\hline \multicolumn{9}{|c|}{ Lower Left } \\
\hline & 5 & 318 & 7.09 & 0.64 & 7.02 & 7.17 & 3.20 & 10.00 \\
\hline & 4 & 318 & 7.04 & 0.52 & 6.98 & 7.10 & 5.00 & 8.50 \\
\hline & 3 & 318 & 6.51 & 0.54 & 6.45 & 6.57 & 4.20 & 8.10 \\
\hline & 2 & 318 & 5.85 & 0.47 & 5.80 & 5.90 & 4.00 & 7.30 \\
\hline & 1 & 318 & 5.41 & 0.52 & 5.35 & 5.47 & 3.00 & 7.40 \\
\hline \multicolumn{9}{|c|}{ Lower Right } \\
\hline & 1 & 318 & 5.42 & 0.52 & 5.36 & 5.48 & 3.00 & 7.60 \\
\hline & 2 & 318 & 5.82 & 0.52 & 5.76 & 5.88 & 4.20 & 7.30 \\
\hline & 3 & 318 & 6.54 & 0.58 & 6.48 & 6.60 & 4.00 & 8.20 \\
\hline & 4 & 318 & 7.05 & 0.51 & 7.00 & 7.11 & 5.40 & 8.40 \\
\hline & 5 & 318 & 7.10 & 0.57 & 7.04 & 7.16 & 5.50 & 10.50 \\
\hline Upper & 2112 & 318 & 30.75 & 2.17 & 30.50 & 30.99 & 22.20 & 36.90 \\
\hline Lower & 2112 & 318 & 22.50 & 1.70 & 22.31 & 22.69 & 16.50 & 27.70 \\
\hline \multicolumn{9}{|l|}{ Upper } \\
\hline Left & 345 & 318 & 21.07 & 1.34 & 20.92 & 21.22 & 16.20 & 24.30 \\
\hline Right & 345 & 318 & 21.03 & 1.24 & 20.89 & 21.17 & 17.30 & 23.90 \\
\hline Both & 345 & 318 & 21.05 & 1.20 & 20.91 & 21.18 & 16.85 & 23.90 \\
\hline Lower & & 318 & & & & & & \\
\hline Left & 345 & 318 & 20.63 & 1.26 & 20.49 & 20.77 & 17.40 & 24.10 \\
\hline Right & 345 & 318 & 20.69 & 1.18 & 20.56 & 20.83 & 17.30 & 23.80 \\
\hline Both & 345 & 318 & 20.67 & 1.14 & 20.54 & 20.80 & 17.65 & 23.95 \\
\hline
\end{tabular}

All measurements to the nearest $0.1 \mathrm{~mm}$

Volume 30 - December 2006 
Table (2) shows the coefficient of correlation between the sum of maxillary and mandibular incisors and the sum of maxillary and mandibular canines and premolars in both groups, in male group, and female group. There was moderate coefficient of correlations between different variables.

Table (2): Coefficient of correlation between different variables

\begin{tabular}{ccccc}
\hline Sum of incisor & $\begin{array}{c}\text { Sum of canine } \\
\text { and premolars }\end{array}$ & (r) for all groups & (r) for male & (r) for female \\
\hline$\underline{21 \mid 12}$ & $\underline{345}$ & 0.475 & 0.404 & 0.48 \\
$\frac{}{21 \mid 12}$ & $\overline{345}$ & 0.573 & 0.630 & 0.487 \\
$\underline{2112}$ & $\underline{345}$ & 0.589 & 0.579 & 0.579 \\
$\underline{2112}$ & $\overline{345}$ & 0.625 & 0.555 & 0.623 \\
\hline
\end{tabular}

Table (3) show regression equation for size prediction of maxillary and mandibular canines and premolars. With the regression analysis from the data obtained in this study equations were derived for the size prediction of maxillary and mandibular canines and premolars.

Table (3): Regression equations for size prediction of maxillary and mandibular canines and premolars

\begin{tabular}{ccccc}
\hline $\mathrm{Y}^{*}$ & $\mathrm{X}^{*}$ & All groups & Male group & Female group \\
\hline$\underline{543}$ & $\underline{21 / 12}$ & $\mathrm{Y}=13.73+0.326 \mathrm{x}$ & $\mathrm{Y}=15.14+0.279 \mathrm{x}$ & $\mathrm{Y}=13.79+0.314$ \\
$\underline{543}$ & $\underline{21 / 12}$ & $\mathrm{Y}=12.20+0.377 \mathrm{x}$ & $\mathrm{Y}=11.97+0.401 \mathrm{x}$ & $\mathrm{Y}=14.08+0.282$ \\
$\underline{543}$ & $\underline{21 / 12}$ & $\mathrm{Y}=11.32+0.317 \mathrm{x}$ & $\mathrm{Y}=12.02+0.304 \mathrm{x}$ & $\mathrm{Y}=11.39+0.309 \mathrm{x}$ \\
$\underline{\mathbf{5 4 3}}$ & $\underline{21 / 12}$ & $\mathrm{Y}=11.28+0.305 \mathrm{x}$ & $\mathrm{Y}=13.24+0.253 \mathrm{x}$ & $\mathrm{Y}=11.43+0.294 \mathrm{x}$ \\
\hline
\end{tabular}

Y sum of maxillary or mandibular canines and premolars of one side $\mathrm{X}$ sum of maxillary or mandibular incisors

Table (4-5) and Figs. $(1,2)$ show the comparison between the predicted width of maxillary and mandibular canines and premolars in this study and the predicted width tabulated in Moyer's chart. The results showed that the $75 \%$ level of the Moyers chart over-estimates the size of the canine and premolars in both maxillary and mandibular arches. 
Table (4)

\begin{tabular}{ccccccc}
\hline $\begin{array}{c}\text { Sum of } \\
\text { mandibular } \\
\text { incisors (mm) }\end{array}$ & $\begin{array}{c}\text { Present } \\
\text { study }\end{array}$ & $5 \%$ & $25 \%$ & $35 \%$ & $50 \%$ & $75 \%$ \\
\hline 19.5 & 20.1 & 18.5 & 19.4 & 19.6 & $20.0^{*}$ & 20.6 \\
20.0 & 20.3 & 18.8 & 19.7 & 19.9 & $20.3 *$ & 20.9 \\
20.5 & 20.4 & 19.0 & 19.9 & $20.2^{*}$ & $20.6^{*}$ & 21.2 \\
21.0 & 20.6 & 19.3 & 20.2 & $20.5^{*}$ & 20.8 & 21.5 \\
21.5 & 20.7 & 19.6 & 20.5 & $20.8^{*}$ & 21.1 & 21.6 \\
22.0 & 20.9 & 19.9 & 20.6 & $21.0 *$ & 21.4 & 22.0 \\
22.5 & 21.1 & 20.1 & $21.0^{*}$ & 21.3 & 21.7 & 22.3 \\
23.0 & 21.2 & 20.4 & $21.3^{*}$ & 21.6 & 21.9 & 22.6 \\
23.5 & 21.4 & 20.7 & $21.6^{*}$ & 21.9 & 22.2 & 22.9 \\
24.0 & 21.6 & 21.0 & $21.9^{*}$ & 22.1 & 22.5 & 23.1 \\
24.5 & 21.7 & $21.2^{*}$ & 22.1 & 22.4 & 22.8 & 23.4 \\
25.0 & & $21.5^{*}$ & 22.4 & 22.7 & & 23.7 \\
& 21.9 & & & & 23.0 & \\
\hline
\end{tabular}

* Result similar to Moyer's Prediction Table

Table (5)

\begin{tabular}{ccccccc}
\hline $\begin{array}{c}\text { Sum of } \\
\text { Mandibular } \\
\text { incisors (mm) }\end{array}$ & $\begin{array}{c}\text { Present } \\
\text { study }\end{array}$ & $5 \%$ & $25 \%$ & $35 \%$ & $50 \%$ & $75 \%$ \\
\hline 19.5 & 19.6 & 17.7 & 18.7 & 19.0 & $19.4^{*}$ & 20.1 \\
20.0 & 19.7 & 18.0 & 19.0 & 19.3 & $19.7^{*}$ & 20.4 \\
20.5 & 19.9 & 18.5 & 19.3 & 19.6 & $20.0^{*}$ & 20.7 \\
21.0 & 20.1 & 18.6 & 19.6 & $19.9 *$ & $20.3 *$ & 21.0 \\
21.5 & 20.3 & 18.9 & 19.9 & $20.2^{*}$ & 20.6 & 21.3 \\
22.0 & 20.5 & 19.2 & 20.2 & $20.5 *$ & 20.9 & 21.6 \\
22.5 & 20.7 & 19.5 & 20.5 & $20.8^{*}$ & 21.2 & 21.9 \\
23.0 & 20.9 & 19.8 & $20.8^{*}$ & 21.1 & 21.5 & 22.2 \\
23.5 & 21.1 & 20.1 & $21.1^{*}$ & 21.4 & 21.8 & 22.5 \\
24.0 & 21.2 & 20.4 & $21.4^{*}$ & 21.7 & 22.1 & 22.8 \\
24.5 & 21.4 & 20.7 & $21.7 *$ & 22.0 & 22.4 & 23.1 \\
25.0 & 21.6 & 21.0 & $22.0^{*}$ & 22.3 & 22.7 & 23.4 \\
\hline
\end{tabular}

* Result similar to Moyer's Prediction Table 

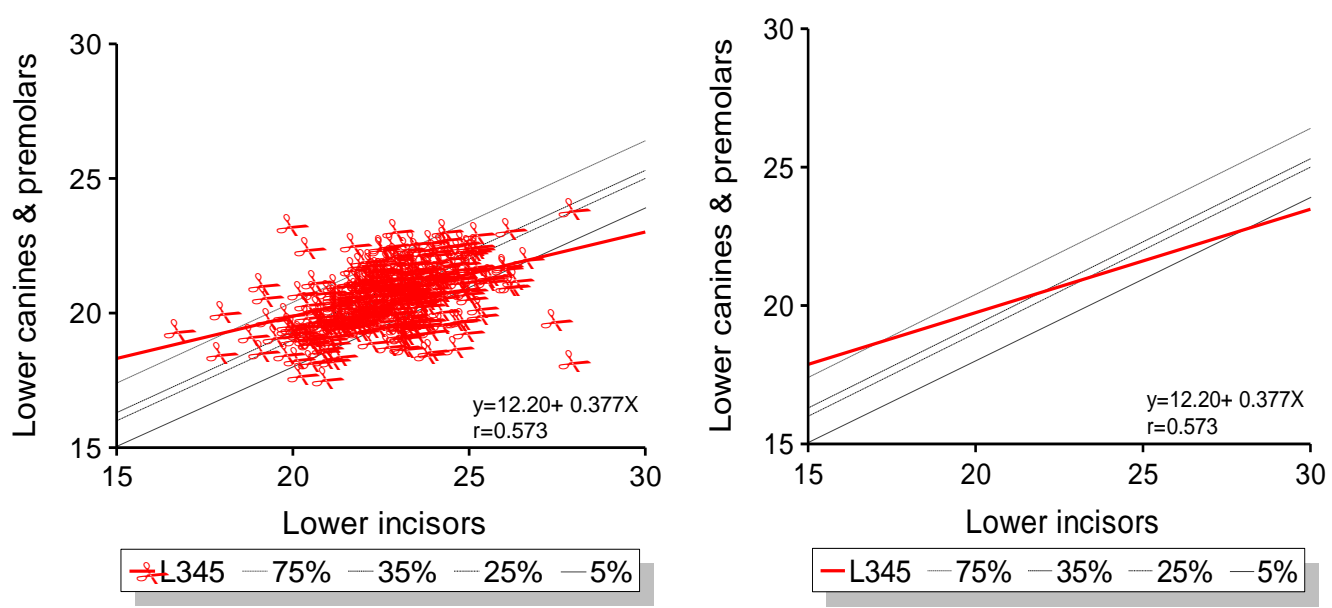

Fig. 1: Diagram to compare between the predicted measurement according to the present study equation and Moyers at different levels in males and females
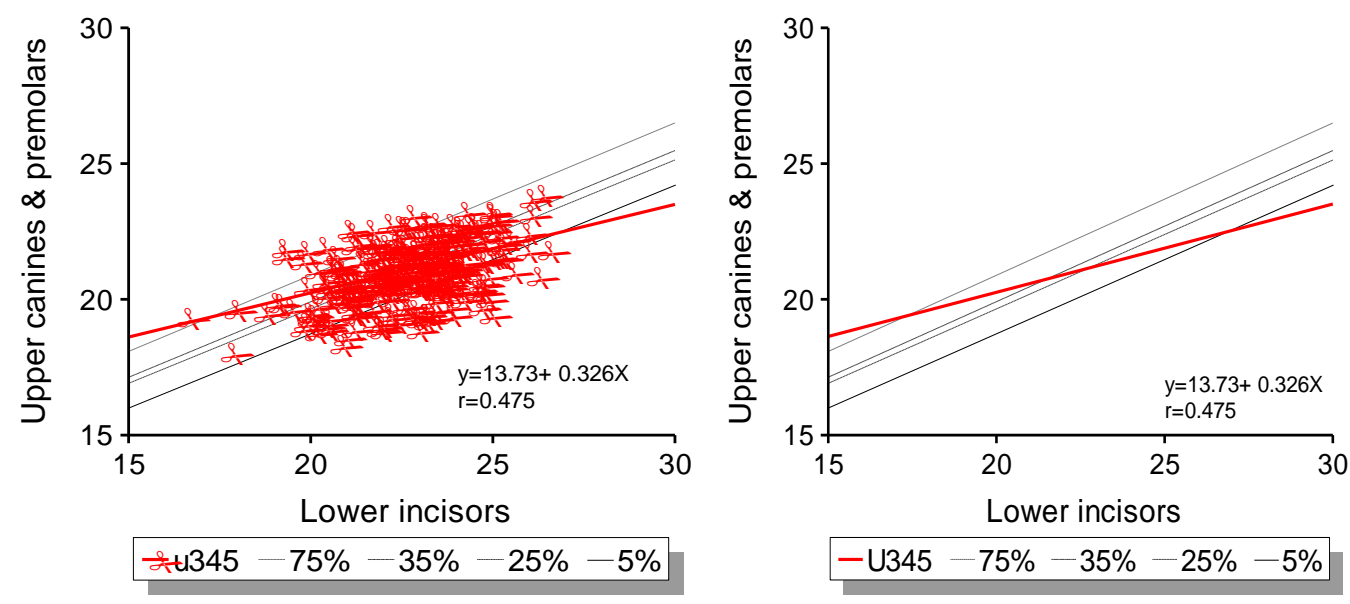

Fig. 2: Diagram to compare between the predicted measurements according to the present study equation and Moyers at different levels in males and females 


\section{Egyptian}

Orthodontic Journal

Table 6: shows prediction chart for the maxillary canine and premolars from the sum of lower incisors at different probability levels 5\%-95\% among males and females.

\begin{tabular}{c|ccccccccccccc}
$\mathrm{X}$ & 19.0 & 19.5 & 20.0 & 20.5 & 21.0 & 21.5 & 22.0 & 22.5 & 23.0 & 23.5 & 24.0 & 24.5 & 25.0 \\
\hline $95 \%$ & 21.5 & 21.7 & 21.9 & 22.0 & 22.2 & 22.3 & 22.5 & 22.7 & 22.8 & 23.0 & 23.2 & 23.3 & 23.5 \\
$85 \%$ & 20.9 & 21.1 & 21.3 & 21.4 & 21.6 & 21.8 & 21.9 & 22.1 & 22.2 & 22.4 & 22.6 & 22.7 & 22.9 \\
$75 \%$ & 20.6 & 20.8 & 20.9 & 21.1 & 21.2 & 21.4 & 21.6 & 21.7 & 21.9 & 22.1 & 22.2 & 22.4 & 22.5 \\
$55 \%$ & 20.3 & 20.5 & 20.6 & 20.8 & 21.0 & 21.1 & 21.3 & 21.4 & 21.6 & 21.8 & 21.9 & 22.1 & 22.3 \\
$50 \%$ & 19.9 & 20.1 & 20.3 & 20.4 & 20.6 & 20.7 & 20.9 & 21.1 & 21.2 & 21.4 & 21.6 & 21.7 & 21.9 \\
$35 \%$ & 19.5 & 19.7 & 19.9 & 20.0 & 20.2 & 20.4 & 20.5 & 20.7 & 20.9 & 21.0 & 21.2 & 21.3 & 21.5 \\
$25 \%$ & 19.3 & 19.4 & 19.6 & 19.8 & 19.9 & 20.1 & 20.2 & 20.4 & 20.6 & 20.7 & 20.9 & 21.1 & 21.2 \\
$15 \%$ & 18.9 & 19.1 & 19.2 & 19.4 & 19.6 & 19.7 & 19.9 & 20.0 & 20.2 & 20.4 & 20.5 & 20.7 & 20.9 \\
$5 \%$ & 18.3 & 18.5 & 18.6 & 18.8 & 19.0 & 19.1 & 19.3 & 19.5 & 19.6 & 19.8 & 19.9 & 20.1 & 20.3 \\
\hline
\end{tabular}

Table 7: shows prediction chart for the mandibular canine and premolars from the sum of lower incisors at different probability levels 5\%-95\% among males and females.

\begin{tabular}{c|ccccccccccccc}
$\mathrm{X}$ & 19.0 & 19.5 & 20.0 & 20.5 & 21.0 & 21.5 & 22.0 & 22.5 & 23.0 & 23.5 & 24.0 & 24.5 & 25.0 \\
\hline $95 \%$ & 20.8 & 21.0 & 21.2 & 21.4 & 21.6 & 21.8 & 22.0 & 22.1 & 22.3 & 22.5 & 22.7 & 22.9 & 23.1 \\
$85 \%$ & 20.3 & 20.5 & 20.7 & 20.9 & 21.0 & 21.2 & 21.4 & 21.6 & 21.8 & 22.0 & 22.2 & 22.4 & 22.6 \\
$75 \%$ & 20.0 & 20.2 & 20.3 & 20.5 & 20.7 & 20.9 & 21.1 & 21.3 & 21.5 & 21.7 & 21.8 & 22.0 & 22.2 \\
$65 \%$ & 19.7 & 19.9 & 20.1 & 20.3 & 20.5 & 20.6 & 20.8 & 21.0 & 21.2 & 21.4 & 21.6 & 21.8 & 22.0 \\
$50 \%$ & 19.4 & 19.6 & 19.7 & 19.9 & 20.1 & 20.3 & 20.5 & 20.7 & 20.9 & 21.1 & 21.2 & 21.4 & 21.6 \\
$35 \%$ & 19.0 & 19.2 & 19.4 & 19.6 & 19.8 & 20.0 & 20.2 & 20.3 & 20.5 & 20.7 & 20.9 & 21.1 & 21.3 \\
$25 \%$ & 18.8 & 18.9 & 19.1 & 19.3 & 19.5 & 19.7 & 19.9 & 20.1 & 20.3 & 20.5 & 20.6 & 20.8 & 21.0 \\
$15 \%$ & 18.4 & 18.6 & 18.8 & 19.0 & 19.2 & 19.4 & 19.6 & 19.8 & 19.9 & 20.1 & 20.3 & 20.5 & 20.7 \\
$5 \%$ & 17.9 & 18.1 & 18.3 & 18.5 & 18.7 & 18.8 & 19.0 & 19.2 & 19.4 & 19.6 & 19.8 & 20.0 & 20.2 \\
\cline { 2 - 9 } & & & & & & & & & & & &
\end{tabular}




\section{Egyptian}

Orthodontic Journal

Table 8: shows prediction chart for maxillary canine and premolars from the sum of upper incisors at different probability levels among males and females.

\begin{tabular}{c|ccccccccccccc}
$\mathrm{X}$ & 27.5 & 28.0 & 28.5 & 29.0 & 29.5 & 30.0 & 30.5 & 31.0 & 31.5 & 32.0 & 32.5 & 33.0 & 33.5 \\
\hline $95 \%$ & 21.6 & 21.7 & 21.9 & 22.0 & 22.2 & 22.3 & 22.5 & 22.7 & 22.8 & 23.0 & 23.1 & 23.3 & 23.5 \\
$85 \%$ & 21.0 & 21.2 & 21.3 & 21.5 & 21.6 & 21.8 & 21.9 & 22.1 & 22.3 & 22.4 & 22.6 & 22.7 & 22.9 \\
$75 \%$ & 20.7 & 20.8 & 21.0 & 21.1 & 21.3 & 21.5 & 21.6 & 21.8 & 21.9 & 22.1 & 22.2 & 22.4 & 22.6 \\
$65 \%$ & 20.4 & 20.6 & 20.7 & 20.9 & 21.0 & 21.2 & 21.3 & 21.5 & 21.7 & 21.8 & 22.0 & 22.1 & 22.3 \\
$50 \%$ & 20.0 & 20.2 & 20.4 & 20.5 & 20.7 & 20.8 & 21.0 & 21.1 & 21.3 & 21.5 & 21.6 & 21.8 & 21.9 \\
$35 \%$ & 19.7 & 19.8 & 20.0 & 20.2 & 20.3 & 20.5 & 20.6 & 20.8 & 21.0 & 21.1 & 21.3 & 21.4 & 21.6 \\
$25 \%$ & 19.4 & 19.6 & 19.7 & 19.9 & 20.1 & 20.2 & 20.4 & 20.5 & 20.7 & 20.8 & 21.0 & 21.2 & 21.3 \\
$15 \%$ & 19.1 & 19.2 & 19.4 & 19.6 & 19.7 & 19.9 & 20.0 & 20.2 & 20.3 & 20.5 & 20.7 & 20.8 & 21.0 \\
$5 \%$ & 18.5 & 18.7 & 18.8 & 19.0 & 19.2 & 19.3 & 19.5 & 19.6 & 19.8 & 20.0 & 20.1 & 20.3 & 20.4 \\
\cline { 2 - 11 } & & & & & & & & & & & & & \\
5
\end{tabular}

Table (9) prediction chart for mandibular canine and premolars from the sum of upper incisor and different probability levels among males and females.

\begin{tabular}{c|ccccccccccccc}
$\mathrm{x}$ & 27.5 & 28.0 & 28.5 & 29.0 & 29.5 & 30.0 & 30.5 & 31.0 & 31.5 & 32.0 & 32.5 & 33.0 & 33.5 \\
\hline $95 \%$ & 21.1 & 21.2 & 21.4 & 21.5 & 21.7 & 21.8 & 22.0 & 22.1 & 22.3 & 22.4 & 22.6 & 22.7 & 22.9 \\
$85 \%$ & 20.5 & 20.7 & 20.8 & 21.0 & 21.2 & 21.3 & 21.5 & 21.6 & 21.8 & 21.9 & 22.1 & 22.2 & 22.4 \\
$75 \%$ & 20.2 & 20.4 & 20.5 & 20.7 & 20.8 & 21.0 & 21.1 & 21.3 & 21.5 & 21.6 & 21.8 & 21.9 & 22.1 \\
$65 \%$ & 20.0 & 20.1 & 20.3 & 20.4 & 20.6 & 20.8 & 20.9 & 21.1 & 21.2 & 21.4 & 21.5 & 21.7 & 21.8 \\
$50 \%$ & 19.7 & 19.8 & 20.0 & 20.1 & 20.3 & 20.4 & 20.6 & 20.7 & 20.9 & 21.0 & 21.2 & 21.3 & 21.5 \\
$35 \%$ & 19.3 & 19.5 & 19.6 & 19.8 & 20.0 & 20.1 & 20.3 & 20.4 & 20.6 & 20.7 & 20.9 & 21.0 & 21.2 \\
$25 \%$ & 19.1 & 19.3 & 19.4 & 19.6 & 19.7 & 19.9 & 20.0 & 20.2 & 20.3 & 20.5 & 20.6 & 20.8 & 20.9 \\
$15 \%$ & 18.8 & 18.9 & 19.1 & 19.3 & 19.4 & 19.6 & 19.7 & 19.9 & 20.0 & 20.2 & 20.3 & 20.5 & 20.6 \\
$5 \%$ & 18.3 & 18.4 & 18.6 & 18.7 & 18.9 & 19.0 & 19.2 & 19.4 & 19.5 & 19.7 & 19.8 & 20.0 & 20.1 \\
\cline { 2 - 8 }
\end{tabular}


Table (10) shows percentage of crowding in the sample of this study. The study recorded a higher percentage of crowding in the lower jaw (36.94\%) in comparison to the upper jaw (21.17\%).

As regard females shows a lower percentage of crowding in both arches, $19.5 \%$ in the upper and $34.5 \%$ in the lower arch ,in relation to males who shows $24.69 \%$ in the upper jaw and $41.25 \%$ in the lower jaw.

\begin{tabular}{cccc}
\hline Variable & Female & Male & Total \\
Crowding in the upper arch & $19.15 \%$ & $24.69 \%$ & $21.17 \%$ \\
Crowding in the lower arch & $34.51 \%$ & 41.25 & $36.94 \%$ \\
\hline
\end{tabular}

Perimeter lesser than tooth materials was considered crowding case

\section{DISCUSSION}

The aim of this study was to evaluate Moyer's mixed dentition analysis in Egyptians. This was done by the application of Moyer's probability chart on an Egyptian sample to assess its applicability or the presence of a deviation resulting from racial difference. It is worth mentioning that Moyer developed his chart based on data derived from a population of Northern European descent. Therefore the accuracy of this prediction method could possibly be in question when applied to a population of different ethnic origin. Furthermore, this study aimed to develop a standard prediction formula to be used for Egyptian population.

In this study an attempt was made to increase the number of the sample as advocated by many authors, (Dowidar 1982, Abdalla 1981, and El-Khadra 1993) in order to develop a chart nearly representing the population.

Generally there are two methods to collect the sample. The first method is by selecting of patients and taking impression and making casts. However, this method may reduce the size of the sample. The other method is by collecting study casts of patients from the records of Orthodontic Department. This latter method was preferable as it increased the size of the sample. The casts were study casts for patient seeking orthodontic treatment whether crowded or spaced. None of them started orthodontic treatment. The casts were free of visible fractures, badly decayed and mal formed tooth or teeth. 
Egyptian

Orthodontic Journal

The mesiodistal crown diameters of the maxillary and mandibular central, lateral incisors, canines, first and second premolars were measured on the casts as the greatest distance between the proximal surfaces of the teeth with the boley gauge graduated to the nearest $0.1 \mathrm{~mm}$ held parallel to the occlusal plane according to Seipel (1946). The perimeter or circumference is the distance or space between the mesial surface of the right first permanent molar and the left permanent molars, in the maxillary or mandibular arch. This distance is occupied by the incisors, canines and premolars. If there is a disproportion between the size of teeth and perimeter, the resultant is crowding or spacing of teeth. In this study the perimeter was measured by the segmented technique.

Application of Moyer's chart for mixed dentition analysis on the Egyptian sample revealed that the $75 \%$ probability confidence level which has been suggested by Moyer's overestimated the mesiodistal widths of upper and lower canines and premolars. This means that the Egyptian population has smaller teeth than the European population which Moyer's chart was developed from. Moreover, 5\%-35\% probability confidence levels were better determination than the commonly used 75\% level as advocated by Moyer.

Furthermore if Moyer's chart was used on Egyptian patients the overestimation in size of the canines and premolar may give a faulty mixed dentition analysis as a result of improper diagnosis and treatment Plan. This in turn may lead to over expansion or extraction treatment plan leaving residual spaces with ultimate failure in treatment. This is in agreement with Kaplan, Smith and Kanarek (1977), Gardner (1979), Abdalla (1981), El-Kathan and Eid (1987), AL-Khadra (1993), Parcherz and Schaffer (1999), Jaroon than and Godfrey (2000), Flores et al., (2003) and Hushim and Al-sholan (2003). This result may be attributed to the racial difference, as well as the difference in the criteria of selection of the patients, whether they had normal occlusion or malocclusion.

There is strong evidence to support the idea that tooth size is largely determined genetically. Marked racial differences exist in the size of teeth, Lapps probably having the smallest teeth while Australian aborigines having the largest (Gran and Lenis 1958 and Gran, Lewis and Walenga, 1968).

Moderate coefficient of correlation was found between the sum of lower incisors and the sum of upper and lower canines and premolars. Moderate coefficient of correlation was also found between the sum of the upper incisors and the sum of upper and lower canines and premolars of one side. Multiple regression analysis was used to develop the equation of the probability chart. 
Due to the sexual dimorphism which was found in the present study, a chart for males and chart for females were made. Also a prediction chart from the lower incisors and prediction chart from the upper incisors were developed.

From the results of this study the following conclusion could be drawn:

1. Moyer's prediction chart was found to be not applicable to the Egyptian sample under the $75 \%$ probability level.

2. The chart overestimated the mesiodistal widths of the upper and lower canine and premolars.

3. The probability confidence levels of Moyer's chart (5\%-35\%) were found to be the nearest prediction figures to the Egyptian sample.

4. A probability chart using the upper incisors was developed depending on the correlation between upper incisors and upper and lower canines and premolars.

5. Prevalence of crowding in the Egyptian sample was found to be $21.2 \%$ in the upper arch and $36.5 \%$ in the lower arch.

\section{REFERENCES}

1. Abdalla, E.M.A.: Arch length analysis in the mixed dentition period, M.S. Thesis Faculty of Dentistry, Alexandria University 1981.

2. Al-Khadra, B.H.: Prediction of the size of unerupted canines and premolars in Saudi Arab Population, Am. J. orthod Dento Facial Orthop. 104 (4): 369-72, 1993.

3. Ballard, M.L and Wylie, W.L.: Mixed dentition case analysis Estimating size of unerupted permenant teeth, Am. J. Orthod. 73; 754-75, 1947.

4. Bernabe, E, Flores-Mir C.: Appraising number and clinical significance of regression equation to predict unerupted canines and premolars, Am. J. Orthod. Dentofacial Orthop.; 126 (2): 228-30, 2004.

5. Black, G.V.: Descriptive anatomy of human teeth, ed. 4 philadelphia, S.S. white Dental MFg. Co. 1897, p. 16 quoted from: Tanaka, M.M and Johnston, L.E. The prediction of the size of unerupted canines and premolars in a contemporary orthodontic population, J. Am. Dent. Assoc. 88 : 798-801, 1974.

6. Dawson, B. and Trapp, G.T.: Basic and clinical biostatistics, 3ed edition, lange medical book, Appleton and lange, Norwalk Connecticut, 2001. 
7. Dowidar, K.S.: Vertification of Moyers arch length analysis on young Egyptian adults; Master degree thesis, Faculty of Dentistry, Alexandria University, 1982.

8. El-Kattan, E.S, Eid, A.A.: A longitudinal study to evaluate Moyers Mixed dentition analysis on a group of Egyptian school children; Egyptian Orthod. J, $1: 139-152,1987$.

9. El-Kattan, E.S, Eid, A.A.: An Egyptian prediction chart for mixed dentition analysis, Egyptian. Orthod. J, 2 : 47-63, 1988.

10. Flores-Mir C, Bernabe, E, Camus C, Carbuayo M.A, Major, P.W.: Prediction of mesiodistal canine and premolar tooth width in a sample of peruvian adolescents, orthod Crani Fus Res., 6 (3): 173-6, 2003.

11. Gardner, R.B.: A comparison of four methods of predicting arch length, Am. J. Orthod. $75:$ 388-398, 1979.

12. Garn, S.M, Lewis, A.B.: Tooth-size, body size and "giant" fassil man; Am. J. Anthropol, $61: 874,1958$.

13. Garn, S.M, Lewis, A.B. and Walenga, A.J.: Maximum confidence value for the human mesiodistal crown dimension of human teeth; Arch. Oral Biol. $13: 841,1968$.

14. Hixon, E.H, Oldfather, R.E.: Estimation of the sizes of unerupted cuspid and bicuspid teeth. Angle. Orthod. 28; 236-40, 1958.

15. Hushim, H.A, Al-Shalan, T.A.: Prediction of the size of unerupted permanent cuspids and bicuspids in a Saudi sample: a pilot study, J Contemp Dent. Pract, 4 (4): 40-53, 2003.

16. Jaroontham, J, Godfrey, K.: Mixed dentition space analysis in a Thai population. Eur J Orthod; 22 (2): 127-34, 2000.

17. Kaplan, R.G, Smith, C.C and Kanarek, P.H.: An analysis of three mixed dentition analysis J. Dent. Res, 56 : 1337-1343, 1977.

18. Macko, D.J, Ferguson, F.S, and Sonnenberg, E.M.: Mesiodistal crown dimensions of permanent teeth of black Americans, J, Dent. Child July. Aug. 42-46, 1979.

19. Moyers,E.R. : Handbook of orthodontics, third edition, year book medical publishers incorporated, 188-92. 
20. Panchez, H., Schaffer, C.: Individual-based prediction of the size of the supporting zones in the permanent dentition. A comparison of the Moyers method with unitary prediction value, J. Orofac. Orthop 60 (1): 227-35, 1999.

21. Siepel, C.M.: Variation of tooth position. A metric study of the variation and adapation in the deciduous and permanent dention. Sversk Quated from al-Khadra, B.H. Am. J Orthod Dentofacial Orthop. 1993 Oct., 104 (4): 369-72. 